\title{
Peer influence as a driver of
} technological innovation in the UK National Health Service: a qualitative study of clinicians' experiences and attitudes

\author{
Claire Greszczuk, ${ }^{1}$ Faraz Mughal, ${ }^{2}$ Rammya Mathew, ${ }^{3}$ Ahmed Rashid ${ }^{4}$
}

- Additional material is published online only. To view please visit the journal online (http://dx.doi.org/10.1136/ bmjinnov-2017-000208).

${ }^{1}$ South London Health Protection Team, Public Health England, London, UK

${ }^{2}$ Warwick Primary Care, University of Warwick, Coventry, West Midlands, UK

${ }^{3}$ Care Quality Improvement Department, Royal College of Physicians, London, UK ${ }^{4}$ University College London Medical School, Royal Free Hospital, London, UK

\section{Correspondence to}

Dr Claire Greszczuk, South London Health Protection Team, Public Health England, London SE16LH, UK; clairegreszczuk@ gmail.com

Received 5 April 2017 Revised 18 October 2017 Accepted 11 January 2018 Published Online First 6 February 2018

\section{Check for updates}

To cite: Greszczuk $C$, Mughal F, Mathew R, et al. BMJ Innov 2018;4:68-74.

\begin{abstract}
Background Accelerating innovation to improve quality is a key policy target for healthcare systems around the world. Effectively influencing individuals' behaviour is crucial to the success of innovation initiatives. This study explores UK clinicians' lived experiences of, and attitudes towards, clinical peers endorsing healthcare innovations.

Methods Qualitative interviews with UK-based clinicians in one of two groups: (1) clinicians working in 'front-line' service provision and (2) clinicians in strategic leadership roles within health institutions. Participants were identified through purposive sampling, and participated in semistructured telephone interviews. Thematic analysis was used to identify and analyse themes in the data.

Results 17 participants were recruited: eight clinicians from front-line UK healthcare settings and nine clinicians in leadership roles. Two major themes were identified from the interviews: power and trust. Participants recognised and valued peers' powerful influence, exerted in person via social networks and routine work-related activities. Peers were implicitly trusted, although often on condition of their credibility and deservingness of respect, supporting evidence and absence of conflict of interest. While the groups shared similar views, they diverged on the subject of institutions, felt to be powerful by strategic leaders yet scarcely mentioned by front-line clinicians.

Conclusions UK clinicians view peers as a powerful and trustworthy source to promote innovative technologies. Policies that aim to support this process should seek to control the wider conditions that nurture peer-to-peer influence. Further research into interpersonal influence in health settings may improve implementation of change initiatives.
\end{abstract}

\section{INTRODUCTION \\ Background}

Amid a climate of financial scarcity, changing public expectations and emerging technologies, health systems internationally are focused on improving healthcare quality and cost efficiency. ${ }^{1}$ The UK Department of Health has included innovation as a key policy target, defining it as 'an idea, service or product, new to the National Health Service (NHS) or applied in a way that is new to the NHS, which significantly improves the quality of health and care. ${ }^{2}$

English institutions, including the National Institute for Health and Care Excellence, ${ }^{3}$ NHS England (NHSE) ${ }^{4}$ and Academic Health Science Networks, ${ }^{5}$ have devolved responsibility for system innovation in England, and employ senior clinicians as leaders of change. Despite their central position, these agencies promote a 'bottom-up' approach to innovation, recognising system change requires engagement and action of individuals through local channels. ${ }^{6}$

Although the macroenvironment is important in health system innovation, adoption and dissemination are contingent on organisational and individual-level change. ${ }^{7}$ For individuals, interpersonal interaction is the fundamental driver of their innovation decision-making. ${ }^{8}$ Interactions between clinicians occur in a variety of settings, including the workplace, conferences and educational events, ${ }^{9} 10$ and behaviours spread though social networks. ${ }^{11}$ Conversations lead to exchange and 
construction of ideas, beliefs and feelings towards innovations and subsequently adoption choices. ${ }^{7}$ In the NHS, clinicians' technology adoption decisions depend on subjective and value-laden notions about the product, termed 'technology identities', which are constructed and perpetuated through social interactions. ${ }^{10}$

'Opinion leaders' (OL) are individuals particularly effective in influencing others' attitudes or behaviour. ${ }^{8}$ Clinicians who share characteristics, clinical backgrounds and social networks, and those who display expertise and competence, are especially influential. ${ }^{812}$ Industries strategically use OL to increase adoption of their products, a practice shown to be effective in influencing doctors' behaviour despite widespread criticism. ${ }^{11} 14$ Industry's influence in today's NHS includes extensive contact with clinicians and active contribution to construction of favourable technology identities. ${ }^{10}$

The place of interpersonal influence in driving innovation may be questioned in today's evidence-based medicine (EBM) era. ${ }^{7}$ Indeed, individuals will only adopt a technology if they perceive it to have relative advantage over alternatives, ${ }^{8}$ implying objective evidence of innovations' effectiveness should be a powerful driver of change. ${ }^{15}$ Early EBM proponents predicted a new age of research rationally translated into practice, ${ }^{16}$ but this has not become a reality. ${ }^{7}$ The innovation adoption process is complex, and scientific evidence does not predict behaviour change. ${ }^{17}$ In the NHS, much practice is non-evidenced, and much evidence never translates into practice. ${ }^{18}$ To explain this evidence-practice gap, it is essential to note 'relative advantage' is not an objective technology attribute, but a subjective perception of potential adopters. ${ }^{8}$ Scientific evidence, often ambiguous, debated and contested, is just one of many factors that shape clinicians' beliefs about technologies and subsequent adoption decisions. ${ }^{710}$

UK health policy explicitly welcomes peer influence, promoting local clinical leadership of innovation. ${ }^{6}$ In contrast, the EBM tradition condemns practice based on non-systematic evidence, ${ }^{15}$ such as personal anecdote and opinion. No studies have specifically explored clinician's attitudes to peers influencing their decisions.

Interpersonal influence is a key driver of clinicians' behaviour, ${ }^{78} 10$ yet it remains unclear how NHS clinicians perceive peer endorsement of innovations. Given its importance in professional decision-making, and the policy context of accelerating innovation, this study sought to understand NHS clinicians' lived experiences of, and attitudes towards, the endorsement of innovative technologies by clinical peers. For this study, 'clinical peer' was defined as a fellow clinician.

\section{METHODS}

\section{Study design}

We performed a qualitative study using semistructured interviews and thematic analysis to explore clinicians'

\begin{tabular}{ll}
\hline Table 1 Terminology \\
\hline Innovation & $\begin{array}{l}\text { As defined by DH: 'an idea, service or product, new to } \\
\text { the NHS or applied in a way that is new to the NHS, } \\
\text { which significantly improves the quality of health and } \\
\text { care wherever it is applied.' }\end{array}$ \\
Technology & $\begin{array}{l}\text { Drugs, devices and diagnostic tools; NICE considers } \\
\text { these 'technologies' in its technology appraisal process. }\end{array}$ \\
Peer & $\begin{array}{l}\text { A fellow clinician. This definition was deliberately broad } \\
\text { to enable participants to interpret the term and respond } \\
\text { based on their personal experiences and perceptions of } \\
\text { their own peers. }\end{array}$ \\
Industry & $\begin{array}{l}\text { Profit-making companies that manufacture and/or supply } \\
\text { health technologies }\end{array}$ \\
\hline
\end{tabular}

DH, Department of Health; NHS, National Health Service; NICE, National Institute for Health and Care Excellence.

experiences of, and attitudes towards, peer clinicians endorsing innovative medical technologies.

\section{Terminology}

The terms 'innovation', 'technology', 'peer' and 'industry' were used frequently. Their definitions, summarised in table 1 , were agreed by the research team and transmitted to the participants during data collection.

\section{Sampling}

CG and AR conducted purposive sampling using their clinical experience and knowledge of prominent NHS institutions to generate a list of potential participants from their professional networks. Participants were chosen to represent two distinct groups:

1. 'Front-line' clinicians who primarily work in service provision

2. 'Strategic leaders' employed in leadership positions within institutions tasked with NHS innovation.

Participants were sought from a range of clinical specialties and NHS institutions to obtain a breadth of experiences and views reflecting the characteristics of UK clinicians. The strategic leaders were selected to provide insight into prominent English institutions, and may or may not have been actively practising alongside their leadership role. The sample was limited to mostly doctors to provide a degree of consistency.

Invitations to participate in a confidential telephone interview were emailed over several weeks; this allowed flexibility to ensure a range of specialties and institutions were represented in the final sample. Recruitment continued until data saturation was reached.

\section{Data collection and analysis}

Semistructured telephone interviews, using an interview guide (see online supplementary appendix 1), were used to allow detailed and flexible exploration of participants' perspectives. Telephone interviews are a valid method and were chosen due to participants' dispersed locations and busy schedules. ${ }^{19}$ Interviews were conducted during October and November 


\begin{tabular}{|c|c|c|c|c|}
\hline Category & Detail & Front-line & $\begin{array}{l}\text { Strategic } \\
\text { leaders }\end{array}$ & Total \\
\hline Number & & 8 & 9 & 17 \\
\hline \multirow[t]{3}{*}{ Level } & Medical consultant & 6 & 8 & 14 \\
\hline & Senior specialist nurse & 0 & 1 & 1 \\
\hline & Medical trainee & $\begin{array}{l}2 \\
\text { GPST } 2 \times 1 \\
\text { ST5 surg.x1 }\end{array}$ & 0 & 2 \\
\hline \multirow[t]{5}{*}{ Specialty } & General practice & 3 & 2 & 5 \\
\hline & Surgical & 2 & 2 & 4 \\
\hline & Medical & 0 & 3 & 3 \\
\hline & Anaesthetics & 2 & 1 & 3 \\
\hline & Paediatrics & 1 & 1 & 2 \\
\hline \multirow{3}{*}{$\begin{array}{l}\text { NHS } \\
\text { commissioning } \\
\text { region }\end{array}$} & London & 3 & 3 & 6 \\
\hline & South & 3 & 4 & 7 \\
\hline & Midlands and East & 2 & 2 & 4 \\
\hline \multirow[t]{5}{*}{$\begin{array}{l}\text { Type of } \\
\text { institution* }\end{array}$} & $\begin{array}{l}\text { NHS arms-length } \\
\text { body }\end{array}$ & - & 5 & 5 \\
\hline & Medical royal college & - & 3 & 3 \\
\hline & AHSN & - & 2 & 2 \\
\hline & Think tank & - & 1 & 1 \\
\hline & $\begin{array}{l}\text { Clinical } \\
\text { commissioning group }\end{array}$ & - & 1 & 1 \\
\hline
\end{tabular}

*Some participants held more than one position.

AHSN, Academic Health Science Network; NHS, National Health Service.

2015 by two researchers (FM and RM). A definition of medical technology was provided to ensure participants did not misinterpret the term. Interviews were audio-recorded, then transcribed and anonymised. Interviews were transcribed and analysed iteratively. After 17 interviews, all four researchers felt data saturation had been reached because no new themes were being identified.

CG, with input from the study team, conducted an inductive thematic analysis of the transcripts. Initial codes were generated representing all interesting features of the data. Related codes and accompanying extracts were collated into potential themes in Microsoft Word. Themes were subsequently reviewed, discussed and refined by the study team to generate the final themes and identify relationships between them. ${ }^{20}$

\section{RESULTS}

\section{Participants}

Seventeen participants were recruited, each participating in one interview. On average, interviews lasted $16 \mathrm{~min}$, and the range was 8-34 min. Participant characteristics are summarised in table 2 .

\section{Themes}

Two major themes were identified: power and trust. Participants recognised and explained peers' powerful influence on behaviour, and identified channels through which it is exerted. Peers were described as trustworthy, although often on condition of their credibility, a supporting evidence base and absence of conflict of interest (COI). Most themes were equally distributed between front-line and strategic leader groups, with one exception, the role of institutions, which arose predominantly among strategic leaders. The themes are considered in turn below. Participants are referred to as (front-line $\mathrm{xx}$ ) or (strategic leader $\mathrm{xx}$ ), where ' $\mathrm{xx}$ ' relates to a unique participant code.

\section{Power}

All participants described peers' powerful influence and offered explanations for why and how it occurs.

\section{Recognised power}

All participants expressly recognised their behaviour is influenced by clinical peers. Several believed peer endorsement is an absolute necessity for adoption:

I'm not sure I can think of examples where peer endorsement and support has not been a factor. (Strategic leader B2)

Three participants noted peers may use their influence to stifle rather than foster innovation, and several others commented on potential for harm if clinicians promote ineffective or non-cost-effective technologies. In contrast, a small number added peers are not necessarily influential:

I have seen TV Doctors speak [at conferences]. I often think, 'Why are they invited?' (...) They don't have anything meaningful to say. (Front-line A1)

Explaining peers' power

Professional value

Most participants explained peers are influential because the clinical community values professionalism and perceives clinicians to understand clinical need:

If not clinical professionals then who? Would you rather hear it from a clinician or someone who has developed the device? I would, for one, hear it from a clinician. (Front-line A6)

\section{Interpersonal contact}

Almost all felt the face-to-face element of peer influence rendered it more impactful than other communication modes:

If you are looking to change practice there is nothing like face-to-face. (...) for me, faceto-face communication remains the most powerful. (Strategic leader B9)

Two participants noted interpersonal interactions also offer an efficient means of information exchange in a time-pressured environment.

Channels of influence

Spread through social networks

Many participants expressed a sense of peer influence spreading powerfully through speciality-specific social 
networks, with endorsements communicated by word of mouth at meetings and among colleagues:

[The laryngeal mask airway] was endorsed within a very few years from China to New Zealand, by every anaesthetic community in every country. (Front-line A3)

\section{Regular and routine contact}

Routine encounters, in the course of day-to-day work and professional development activities, were identified as another pervasive and powerful source of peer influence:

My practice has been led by a consultant-led GP education evening, where the ENT consultant (...) presented the data and said, 'This is the product I recommend.' (Front-line A2)

\section{A role for institutions}

Most strategic leader participants demonstrated faith in institutions' role in facilitating peer endorsement of innovations:

I suspect the only other route is through the
innovation portals of AHSNs. That's the other
organisation that should be coordinating local level
endorsement, and clinicians should be doing so
through their AHSN. (Strategic leader B3)

In sharp contrast, only one front-line doctor mentioned an institution: a noteworthy discrepancy between the groups.

\section{Trust}

Trust was central to all participants' accounts of peer influence. Peers were deemed trustworthy on condition of credibility and deservingness of respect, a supporting evidence base and no COI.

\section{Credibility and respect}

Most participants implied peers are a more trustworthy source of information than non-clinicians due to their clinical credentials:

As a GP, most of the clinical updates I attend are led by clinicians (...) I perceive that to be more trustworthy than a non-clinical person doing it. (Front-line A2)

'Local' or 'known' peers were viewed as particularly credible, as were prominent figures with authority or prestige. Some described different 'criteria' for credibility between specialties:

To be credible as a physician, it is often about the titles after your name and your academic weight in publication. (...) If you want to get a surgical innovation into the market, you get someone who is the guy, when you have your gallbladder [out] you would go and see. (Strategic leader B1)
One participant recognised the likelihood of cognitive bias in favour of an innovation if it were endorsed by a well-known figure, and several others acknowledged they were more likely to trust a skilful orator.

\section{Evidence base}

All participants believed endorsement should ideally be evidence based, but views concerning the weight of science in relation to peer influence varied. Several felt an evidence base is an absolute necessity to trust a clinician endorsing a novel technology, and disapproved of peers endorsing without robust evidence:

There is no point in a clinician standing up and saying 'I think this is bloody marvellous.' It has got to stand up robust evaluation. (Strategic leader B8)

Four participants highlighted how useful peer opinion can be when the evidence base is limited, and over half of the group believed peer influence, including opinion and anecdote, can be more powerful than evidence for influencing adoption:

The profession is far more influenced by anecdote and our friends talking enthusiastically about a new piece of kit than a large multi-centred trial. (Strategic leader B1)

Conflict of interest

All but one participant raised the issue of COI, most implying their trust in a peer would be damaged if COI were present or transparency lacking. In addition, most expressed mistrust of industry and disapproval of company-employed clinicians:

Improving the health of the nation (...) is not [industry's] primary interest. Their primary interest is selling a product. (Front-line A8)

In contrast, four participants felt COI is not necessarily a reason to mistrust a clinician endorsing a technology, especially where they have been involved in its evaluation:

I think [COI] is grossly overplayed. Then you end up with the opposite, you have people with no conflict of interest but haven't got a clue what they're talking about. (Strategic leader B2)

Figure 1 is a thematic map, displaying the themes and subthemes described above.

\section{DISCUSSION}

This study found clinical peers are considered a powerful and trustworthy influence on adoption behaviour, although trust is often conditional on perceived credibility, evidence base and absence of COI. Peer endorsement is encountered regularly and valued as an appropriate and useful influence. Frontline and strategic leader clinicians shared strikingly similar views, diverging only on the role of institutions, with strategic leaders placing greater emphasis 


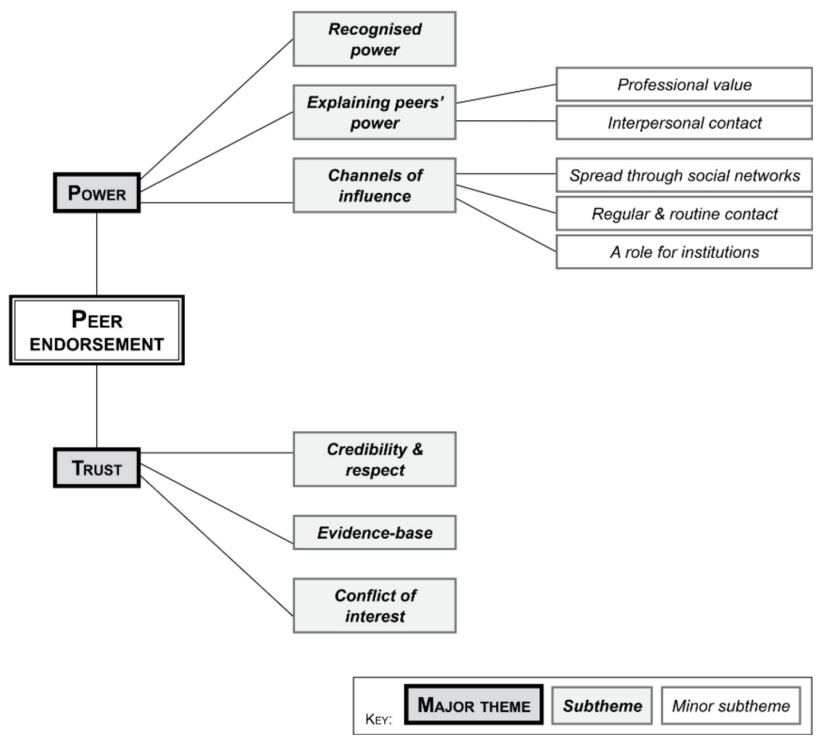

Figure 1 Thematic map.

on institutions' power. Inconsistencies and contradictions throughout the data highlight the complexity of individuals' decision-making processes.

All participants recognised peer endorsement has a powerful influence, spreading through social networks and face-to-face interactions, and occurring regularly during daily work and professional development. Although this acknowledgement contrasts with psychological literature describing how people typically underestimate the impact of others' influence on their own behaviour, ${ }^{21}$ UK general practitioners have previously been shown to cite specialist recommendation as an important determinant of their prescribing choices. ${ }^{22}$ The active promotion of peerto-peer learning in UK medical practice may explain why participants so clearly recognised peer influence and commonly experience it. ${ }^{23}$

Interpersonal interaction with peers was considered more powerful than distant, impersonal communication, aligning with classical innovation adoption models, which state interpersonal influence is the fundamental driver of adoption, especially for complex innovations. ${ }^{8}$ Additionally, participants cited overwhelming NHS time pressures, an acknowledged barrier to innovation, ${ }^{24}$ as further explanation for the powerful impact of interpersonal contact, where peerto-peer recommendations represent an efficient and trusted information source.

On trust, while peers were typically viewed as trustworthy individuals, this often depended on their perceived credibility, resembling previous work on OL in the NHS, which recognised two distinct groups of influential leader: 'peer-like' and 'expert'. ${ }^{25}$ Participants implied credibility 'criteria' vary between specialties, consistent with research suggesting opinion leadership depends on the audience and stage of innovation: prestigious or specialised clinicians may be influential at an early stage of invention whereas local and trusted peers represent a powerful influence for front-line implementation. ${ }^{25}$

Robust supporting evidence was another prominent proviso for trust. The prevailing EBM paradigm, which prioritises scientific knowledge and trains clinicians to practise accordingly, may explain this. ${ }^{1516}$ While clinicians have been shown to use evidence inconsistently and subjectively to construct and perpetuate beliefs about technologies, ${ }^{710}$ the findings imply consideration and interpretation of evidence is nonetheless a valued pillar of clinical decision-making. That said, many participants acknowledged interpersonal influence can outweigh research evidence, consistent with the evidence-practice gap seen in the NHS. ${ }^{717}$

COI was another major barrier to trust. Mistrust of industry and scepticism towards peers with COI was notable, aligning with the backdrop of widespread cynicism towards industry, ${ }^{13}$ and extensive marketing targeted at NHS clinicians. ${ }^{10} \mathrm{~A}$ small minority felt $\mathrm{COI}$ is expected and acceptable however, arguing it is uncommon to find a credible OL without COI, indicating a nuanced picture exists in which perception of trustworthiness may be more powerful than objective truths.

The single noteworthy divergence between the front-line and strategic leader clinicians was on institutions as powerful facilitators of peer endorsement. While the strategic leaders may have simply been displaying greater awareness of institutions and their roles, it nonetheless suggests institutions hold a distinct lack of relevance for front-line clinicians. UK doctors have previously been found to place little importance on formal organisational position or authority of OL, favouring those with clinical or academic credibility. ${ }^{25}$ This view may be deep rooted in medical professionalism, in which clinical nous is prized and doctors feel their practice is hampered by health system politics and culture. ${ }^{26}{ }^{27}$ Furthermore, while institutions may facilitate innovation by controlling the contextual and organisational environment, ${ }^{28}$ they are weak in affecting complex social processes at an individual level. ${ }^{72}$ Considering the current policy focus on locally led innovation, ${ }^{6}$ the strategic leaders may have overestimated institutions' power to influence peer-led change.

Participants clearly approved of peer influence, recognising the importance of involving expert stakeholders in organisational change, ${ }^{30}$ and valuing the autonomy and expertise reserved for, and increasingly defended by, the medical profession. ${ }^{26} 27$

In contrast, unfavourable attitudes towards peer endorsement were also evident. The participants' disapproval of peers using anecdotal evidence highlighted how the EBM paradigm has permeated clinicians' value system. ${ }^{15} 1624$ Regarding COI, negative attitudes towards sales and marketing were expressed with great consistency and clarity, illuminating mistrust of industry among the medical community. ${ }^{13}$ Several participants 
acknowledged peer influence could be detrimental if it caused inefficient NHS resource allocation. ${ }^{16}$

\section{Study strengths and limitations \\ Strengths}

The diverse range of participants in this study provided a variety of opinions from across the medical profession. The qualitative design suited exploration of complex social processes, and the use of robust methodology ensured a high-quality data set and analysis were achieved.

\section{Limitations}

The research team exclusively comprised clinicians and may have had a more detailed theoretical basis if it included social scientists. However, this meant the study adopted a 'real-world' focus. As the research team come from NHS clinical backgrounds this may have influenced their perspectives in recognising themes. Furthermore, participants did not review and comment on the final themes due to resource limitations. However, the team members independently reviewed the data, discussed areas of disagreement and came to a consensus on the final themes to mitigate these issues. The study examined practices within three NHSE regions. While the findings provide valuable insights from a small number of clinicians, they may not represent the rest of England or other health systems around the world.

\begin{abstract}
Acknowledgements We thank M Choudhury who assisted with applying for ethical approval, and E Protopapa, who provided guidance on data analysis. We also thank all participants for their time and commitment to our study.
\end{abstract}

Contributors CG and AR were responsible for study concept and design, sampling and participant recruitment. RM and FM were responsible for data acquisition. CG led the data analysis, with contribution from all authors. CG led the drafting of the manuscript, with contribution from all authors. All authors contributed to critical revision of the manuscript.

Funding This research received no specific grant from any funding agency in the public, commercial or not-for-profit sectors.

Competing interests None declared.

Ethics approval The study was approved by The University of Sheffield School of Health and Related Research (ScHARR) Research Ethics Committee (ref: NICE008).

Provenance and peer review Not commissioned; externally peer reviewed.

Data sharing statement The study team have access to the interview transcripts (which will be permanently deleted in December 2017 as pre-agreed at the beginning of the study). No additional unpublished data are otherwise available.

(c) Article author(s) (or their employer(s) unless otherwise stated in the text of the article) 2018. All rights reserved. No commercial use is permitted unless otherwise expressly granted.

\section{REFERENCES}

1 Great Britain, Department of Health. Annual report and accounts 2015-16. London: Stationary Office, 2016. https:// www.gov.uk/government/uploads/system/uploads/attachment data/file/539602/DH_Annual_Report_Web.pdf.

2 Great Britain, Department of Health. Innovation, health and wealth: accelerating adoption and diffusion in the
NHS. London: Stationary Office, 2011a. http://webarchive. nationalarchives.gov.uk/20130107105354/http:/www.dh. gov.uk/prod_consum_dh/groups/dh_digitalassets/documents/ digitalasset/dh_134597.pdf.

3 The National Institute of Health and Care Excellence (NICE). What we do. https://www.nice.org.uk/about/what-we-do.

4 NHS England. Annual report 2015/16. London: Stationary Office, 2016. https://www.england.nhs.uk/wp-content/uploads/ 2016/07/nhse-annual-rep-201516.pdf.

5 NHS England. Our work: partnerships and relationships: academic health science networks. https://www.england.nhs.uk/ ourwork/part-rel/ahsn/.

6 Great Britain, Department of Health. Examining new options and opportunities for providers of NHS care: the dalton review. 2014 https://www.gov.uk/government/uploads/system/ uploads/attachment_data/file/384126/Dalton_Review.pdf.

7 Greenhalgh T, Robert G, Bate P, et al. How to spread good ideas. A systematic review of the literature on diffusion, dissemination and sustainability of innovations in health service delivery and organisation. Report for the National Coordinating Centre for NHS Service Delivery and Organisation $R$ o D. London: NCCSDO, 2004:1-426.

8 Rogers EM. Diffusion of innovations. New York: Free Press, 1995.

9 Flodgren G, Parmelli E, Doumit G, et al. Local opinion leaders: effects on professional practice and health care outcomes. Cochrane Database Syst Rev 2011:CD000125.

10 Tomlin Z, Peirce S, Elwyn G, et al. The adoption space of earlyemerging technologies: evaluation, innovation, gatekeeping (PATH). Final report: NIHR Service Delivery and Organisation programme, 2012.

11 West E, Barron DN, Dowsett J, et al. Hierarchies and cliques in the social networks of health care professionals: implications for the design of dissemination strategies. Soc Sci Med 1999;48:633-46.

12 Adler PS, Riley P, Kwon S-W, et al. Performance improvement capability: keys to accelerating performance improvement in hospitals. Calif Manage Rev 2003;45:12-33.

13 Blumenthal D. Doctors and drug companies. N Engl J Med 2004;351:1885-90.

14 Brennan TA, Rothman DJ, Blank L, et al. Health industry practices that create conflicts of interest: a policy proposal for academic medical centers. JAMA 2006;295:429-33.

15 Guyatt G; Evidence-Based Medicine Working Group. Evidence-based medicine. A new approach to teaching the practice of medicine. JAMA 1992;268:2420-5.

16 Guyatt GH, Haynes RB, Jaeschke RZ, et al. Users' guides to the medical literature: XXV. Evidence-based medicine: principles for applying the users' guides to patient care. JAMA 2000;284:1290-6.

17 Grol R. Improving the quality of medical care: building bridges among professional pride, payer profit, and patient satisfaction. JAMA 2001;286:2578-85.

18 NHS England, Public Health England and NHS Right Care. NHS Atlas of variation in healthcare. 2015 http://www.rightcare. nhs.uk/index.php/atlas/nhs-atlas-of-variation-in-healthcare-2015/

19 Green J, Thorogood N. Qualitative methods for health research. London: SAGE Publications, 2014.

20 Braun V, Clarke V. Using thematic analysis in psychology. Qual Res Psychol 2006;3:77-101.

21 Nolan JM, Schultz PW, Cialdini RB, et al. Normative social influence is underdetected. Pers Soc Psychol Bull 2008;34:913-23. 
22 Prosser H, Almond S, Walley T. Influences on GPs' decision to prescribe new drugs-the importance of who says what. Fam Pract 2003;20:61-8.

23 General Medical Council. Good Medical Practice. 2014. http:// www.gmc-uk.org/static/documents/content/GMP_.pdf.

24 Greenhalgh T, Howick J, Maskrey N; Evidence Based Medicine Renaissance Group. Evidence based medicine: a movement in crisis? BMJ 2014;348:g3725.

25 Locock L, Dopson S, Chambers D, et al. Understanding the role of opinion leaders in improving clinical effectiveness. Soc Sci Med 2001;53:745-57.

26 Working Party of the Royal College of Physicians. Doctors in society. Medical professionalism in a changing world. Clin Med 2005;5(6 Suppl 1):S5-40.
27 Thorne ML. Colonizing the new world of NHS management: the shifting power of professionals. Health Serv Manage Res 2002;15:14-26.

28 Kanter RM. When a thousand flowers bloom: structural, collective and social conditions for innovation in organisation. In: Staw BM, Cummings LL, eds. Research in organisational behaviour. Greenwich, CT: JAI Press, 1988.

29 Fonseca J. Complexity and innovation in organisations. London: Routledge, 2001.

30 Iles V, Sutherland K. Managing change in the NHS. Organisational change: a review for health care managers, professionals and researchers. Report for the National Co-ordinating Centre for NHS Service Delivery and Organisation R \& D. London: NCCSDO, 2001. 